Article

\title{
Room-Temperature Reduction of Graphene Oxide in Water by Metal Chloride Hydrates: A Cleaner Approach for the Preparation of Graphene@Metal Hybrids
}

\author{
Patrick. P. Brisebois ${ }^{1}$, Ricardo Izquierdo ${ }^{2}$ and Mohamed Siaj ${ }^{1, *(1)}$ \\ 1 Department of Chemistry, Université du Québec à Montréal, NanoQAM/QCAM, Montreal, QC H3C 3P8, \\ Canada; patb.office@gmail.com \\ 2 École de Technologie Supérieure, Université du Québec, Montreal, QC H3C 1K3, Canada; \\ ricardo.izquierdo@etsmtl.ca \\ * Correspondence: siaj.mohamed@uqam.ca; Tel.: +1-514-987000 (ext. 1921)
}

Received: 18 May 2020; Accepted: 16 June 2020; Published: 28 June 2020

\begin{abstract}
Headed for developing minimalistic strategies to produce graphene@metal hybrids for electronics on a larger scale, we discovered that graphene oxide (GO)-metal oxide (MO) hybrids are formed spontaneously in water at room temperature in the presence of nothing else than graphene oxide itself and metal ions. Our observations show metal oxide nanoparticles decorating the surface of graphene oxide with particle diameter in the range of $10-40 \mathrm{~nm}$ after only $1 \mathrm{~h}$ of mixing. Their load ranged from $0.2 \%$ to $6.3 \%$ depending on the nature of the selected metal. To show the generality of the reactivity of GO with different ions in standard conditions, we prepared common hybrids with GO and tin, iron, zinc, aluminum and magnesium. By means of carbon-13 solid-state nuclear magnetic resonance using magic angle spinning, we have found that graphene oxide is also moderately reduced at the same time. Our method is powerful and unique because it avoids the use of chemicals and heat to promote the coprecipitation and the reduction of GO. This advantage allows synthesizing GO@MO hybrids with higher structural integrity and purity with a tunable level of oxidization, in a faster and greener way.
\end{abstract}

Keywords: graphene oxide; chloride hydrates; ${ }^{13} \mathrm{C}$ NMR spectroscopy; metal oxide

\section{Introduction}

Graphene oxide (GO) is regarded as a major precursor of graphene-based metal (M) and metal oxide (MO) particle nanocomposites, important building blocks for electronic and electrochemical devices [1-5]. The presence of oxygen atoms and metal particles in the composite can change dramatically the physical, electronic and chemical properties of graphene-based devices [4]. GO@M/MO materials have shown great promises in various hi-tech application fields such as paramagnetic agents for magnetic resonance imaging $(\mathrm{M}=\mathrm{Fe})$ [6-8], capacitive electrodes for lithium batteries $(\mathrm{M}=\mathrm{Fe}$, $\mathrm{Co}, \mathrm{Sn})[9,10]$, supercapacitors $(\mathrm{M}=\mathrm{Cu}, \mathrm{Ti}, \mathrm{Mn})$ [11-14], photocatalysts $(\mathrm{M}=\mathrm{Ti}, \mathrm{Sn}, \mathrm{W})$ [15-20], electrocatalysts $(\mathrm{M}=\mathrm{Au}, \mathrm{Pd}, \mathrm{Pt})$ [21-23], catalysts for chemical transformation $(\mathrm{M}=\mathrm{Au}, \mathrm{Pt})[24,25]$, electrodes $(\mathrm{M}=\mathrm{Ti}, \mathrm{Zn})[26,27]$, conductive transparent films $(\mathrm{M}=\mathrm{Cu})[28]$, sensing $[29,30](\mathrm{M}=$ $\mathrm{Sn}, \mathrm{Pd}, \mathrm{Zn})$ [31-35], water remediation $(\mathrm{M}=\mathrm{Fe})$ [36,37], molecular separation [38] and antibacterial nanocomposites ( $\mathrm{M}=\mathrm{Ag}, \mathrm{Cu}, \mathrm{Zn}, \mathrm{Mn}, \mathrm{Se}$ ) [39,40]. According to previous reports [41], $\mathrm{C}-\mathrm{OH}$ on $\mathrm{GO}$ can easily react with metal cations to form $\mathrm{C}-\mathrm{O}-\mathrm{M}$.

GO has the ability to make chemical and physical interactions with different metal or metal oxide through others oxygenated defects as well [4]. A recent study showed that most of C-O-M bonds 
are from the reaction between epoxy and metal oxide and/or hydroxide, while only a part of $\mathrm{C}-\mathrm{O}-\mathrm{M}$ bonds could be explained by GO's carboxyl $(\mathrm{C}=\mathrm{O})$ and hydroxy $(\mathrm{C}-\mathrm{OH})$ groups. Evidence was mainly collected from infrared (FTIR) and X-ray photoemission spectroscopy (XPS) data.

Several methods $[1,2]$ are available to prepare GO@M/MO composites on a gram scale using the solution mixing method [42], the sol-gel method [43], the hydrothermal/solvothermal method under pressure and heat [38], by self-assembly [44] or conjugation [30] with preformed particles, by spontaneous redox reaction between metal and GO in solution [31] or by dry mechanomecanical metal reduction of GO [45]. When mixed together in solution, metal ions of different nature can be coprecipitated to form binary metals systems on GO [46-48]. The usual solvents used in the precipitation method are water, water-ethanol [42] mixtures or dimethylformamide (DMF) [32]. To achieve the in-situ covalent binding or loading of metal and metal oxide nanoparticles (NPs) on GO's surface, heat, microwave irradiation [23] or UV irradiation [49] are always used in combination with chemicals $[1,2,4,50]$. The most employed chemicals used in these transformations are: hydrazine [46], sodium borohydride [51] or glucose [52] as reducing agents; sodium or potassium hydroxide and hydrochloric acid as pH adjusters [46] and surfactants [43]. Noteworthy, all these methods lead to GO with a higher degree of reduction, hence called reduced graphene oxide (rGO).

Unfortunately, approaches using chemicals and extreme conditions entail structural damages and result in the breaking of graphene oxide sheets into smaller fragments [52]. Every time GO is mixed with a reagent containing heteroatoms, some will likely be trapped and will remain in the composite as an impurity (doping). Furthermore, it is very difficult to control the size and shape of the NPs during their formation at high temperature. Those factors have a great impact on the efficacy of the material for a specific application because they affect the mechanical properties and the electronic bandgap of the material $[6,53]$. The key challenge to improve the performance of the GO@M/MO composite is to develop a milder synthesis to avoid these problems [54-56].

Herein, we addressed these issues and have found a way to avoid the use of any chemicals, heat or irradiation to synthetize high purity GO@MO hybrids with minimal defects. We developed a minimalistic very mild method using only $\mathrm{GO}$ and concentrated aqueous solutions ( $1 \mathrm{M})$ of metal chloride hydrates $\left(\mathrm{SnCl}_{2} \cdot 2 \mathrm{H}_{2} \mathrm{O}, \mathrm{FeCl}_{2} \cdot 4 \mathrm{H}_{2} \mathrm{O}, \mathrm{ZnCl}_{2} \cdot 2 \mathrm{H}_{2} \mathrm{O}, \mathrm{AlCl}_{3} \cdot 6 \mathrm{H}_{2} \mathrm{O}\right.$ or $\left.\mathrm{MgCl}_{2} \cdot 6 \mathrm{H}_{2} \mathrm{O}\right)$, which have a natural acidic $\mathrm{pH}$. Our observations show the room temperature formation of metal oxide nanoparticles decorating the surface of GO, while our carbon-13 solid-state nuclear magnetic resonance (13C SS-NMR) data show a moderate reduction of GO compared to the starting material. All our materials were further characterized using transmission electronic microscopy (TEM), thermogravimetric analysis (TG/DTGA), Fourier transform infrared (FTIR), X-ray photoelectron (XPS), energy-dispersive X-ray (EDS) and Raman spectroscopy techniques, giving a hint on how metal oxides can form in the absence of external stimuli.

\section{Experimental}

\subsection{Synthesis of Graphene Oxide}

Graphene oxide was prepared using a modified procedure of the Hummer's method developed by Tours and collaborators [57]. Briefly, Graphite ( $3 \mathrm{~g})$ was mixed with $\mathrm{H}_{2} \mathrm{SO}_{4}(360 \mathrm{~mL})$ and $\mathrm{H}_{3} \mathrm{PO}_{4}$ $85 \%(40 \mathrm{~mL})$. Then, the mixture was heated to $50{ }^{\circ} \mathrm{C}$ and stirred while $\mathrm{KMnO}_{4}(18 \mathrm{~g})$ was added slowly over $5 \mathrm{~min}$. Short periods of ultra-sonication $(4 \times)$ were applied every hour $(15 \mathrm{~min})$ over the course of the reaction $(4 \mathrm{~h})$ to favor exfoliation. Once the reaction was completed, the thick mixture was allowed to cool down to room temperature and was neutralized slowly over a mixture of ice (600 g) and hydrogen peroxide $30 \%(10 \mathrm{~mL})$ with strong evolution of gas. The crude GO was recovered using centrifugation (10,000 RPM, $2 \mathrm{~h}$ ) and the brown solids were washed successively with $200 \mathrm{~mL}$ of water, $200 \mathrm{~mL}$ of $\mathrm{HCl} 10 \%$ and $500 \mathrm{~mL}$ of anhydrous ethanol (2×). The material was finally precipitated in anhydrous ether $(1000 \mathrm{~mL})$ and recovered using vacuum filtration over a Teflon ${ }^{\circledR}$ membrane $(0.45 \mu \mathrm{m})$. 
The light brown material was dried under vacuum $(24 \mathrm{~h})$ below $40{ }^{\circ} \mathrm{C}$ yielding $5.9 \mathrm{~g}$ of a mixture of graphene/graphite oxide.

The crude material $(5.9 \mathrm{~g})$ containing a mixture of graphite and graphene oxide was suspended in NanoPure water $(1 \mathrm{~L})$ using stirring $(12 \mathrm{~h})$ and sonication $(60 \mathrm{~min})$ until complete homogenization. Some unreacted graphitic particles and thick multilayers were still visible in the suspension and were removed by centrifugation ( 5000 rotation per minute (RPM), $30 \mathrm{~min}$ ). The large intact graphene oxide flakes were recovered using centrifugation at 10,000 RPM (2 h) and the smaller flakes were eliminated in the remaining liquid. The portion containing the intact sheets (10,000 RPM) was recovered as a hydrogel and was freeze-dried under vacuum to remove water completely. The solid material was dried below $40{ }^{\circ} \mathrm{C}$ under high vacuum $(24 \mathrm{~h})$ and stored in a sealed desiccator over $\mathrm{P}_{2} \mathrm{O}_{5}$ for one week, yielding $5.2 \mathrm{~g}$ of dehydrated graphene oxide.

\subsection{Preparation of Aqueous Suspension of GO}

Dehydrated graphene oxide $(1 \mathrm{~g})$ was suspended in NanoPure water $(200 \mathrm{~mL})$ using sonication $(30 \mathrm{~min} \times 2)$ and stirring $(12 \mathrm{~h} \times 2)$ at room temperature resulting in an aqueous homogenous suspension of $5 \mathrm{mg} \mathrm{mL}^{-1}$.

\subsection{Preparation of $2 M$ Aqueous Solution of Metal Chloride}

Metal chlorides $\left(0.4 \mathrm{~mol}\right.$ ) such as $\mathrm{SnCl}_{2} \cdot 2 \mathrm{H}_{2} \mathrm{O}, \mathrm{FeCl}_{2} \cdot 4 \mathrm{H}_{2} \mathrm{O}, \mathrm{ZnCl}_{2}, \mathrm{AlCl}_{3} \cdot 6 \mathrm{H}_{2} \mathrm{O}$ and $\mathrm{MgCl}_{2} \cdot 6 \mathrm{H}_{2} \mathrm{O}$ were dissolved separately in NanoPure water $(200 \mathrm{~mL})$ using stirring $(1 \mathrm{~h})$ at room temperature resulting in a $2 \mathrm{M}$ aqueous solution. In the case of $\mathrm{SnCl}_{2} \cdot 2 \mathrm{H}_{2} \mathrm{O}$ and $\mathrm{FeCl}_{2} \cdot 4 \mathrm{H}_{2} \mathrm{O}$, a saturated solution was obtained and used as prepared without filtration of the insoluble particles.

\subsection{Synthesis of GO@MO Hybrids}

GO suspension $\left(200 \mathrm{~mL}, 5 \mathrm{mg} \mathrm{mL}^{-1}\right)$ was added rapidly in a beaker over the $2 \mathrm{M}$ aqueous solution of metal chlorides $\left(200 \mathrm{~mL}\right.$ ) (e.g., $\mathrm{SnCl}_{2} \cdot 2 \mathrm{H}_{2} \mathrm{O}, \mathrm{FeCl}_{2} \cdot 4 \mathrm{H}_{2} \mathrm{O}, \mathrm{ZnCl}_{2} \cdot 4 \mathrm{H}_{2} \mathrm{O}, \mathrm{AlCl}_{3} \cdot 6 \mathrm{H}_{2} \mathrm{O}$ or $\mathrm{MgCl}_{2} \cdot 6 \mathrm{H}_{2} \mathrm{O}$ ), resulting in a final suspension $\left(400 \mathrm{~mL}\right.$ ) with a concentration of $1 \mathrm{M}$ in metal ions and $2.5 \mathrm{mg} \mathrm{mL}^{-1}$ in GO. The mixture was stirred vigorously for $1 \mathrm{~h}$ at room temperature $\left(24^{\circ} \mathrm{C}\right)$ and atmospheric pressure (standard conditions) using magnetic stirring. During the reduction, the color of GO changed from orange to light brown and the $\mathrm{pH}$ of the solutions was evaluated using paper strips. After the reaction, the hybrid materials were recovered using centrifugation (10,000 RPM, $2 \mathrm{~h}$ ). The supernatant liquid containing metal ions was collected aside and recycled for a further reaction with GO. Then, the materials were washed successively with $200 \mathrm{~mL}$ of $\mathrm{HCl} 5 \%(3 \times)$ and with $200 \mathrm{~mL}$ of deionized water $(3 \times)$ to remove free particles of metal oxide. The brown materials were freeze-dried under vacuum to remove water completely. Then, they were dried below $40{ }^{\circ} \mathrm{C}$ under high vacuum $(24 \mathrm{~h})$ and stored in a sealed desiccator over $\mathrm{P}_{2} \mathrm{O}_{5}$ for one week prior to analysis, yielding $0.8-1.2 \mathrm{~g}$ of dehydrated GO@MO composites.

\subsection{Characterization Methods}

${ }^{13} \mathrm{C}$-SS MAS-NMR spectra were recorded with Bruker Avance III HD spectrometer (Milton, ON, Canada) operating at frequencies of $150.874 \mathrm{MHz}$ for ${ }^{13} \mathrm{C}$ and $599.84 \mathrm{MHz}$ for ${ }^{1} \mathrm{H}$ using a 4-mm magic-angle spinning (MAS) double resonance probe and a zirconium oxide rotor for NMR analysis. Magic angle spinning was performed at a spinning frequency of $12.5 \mathrm{kHz}$. Typically, $100 \mathrm{mg}$ of GO material or hybrid was used in the sample and 4096 scans were recorded (or otherwise specified) to achieve desired spectral resolution. Direct Pulse- ${ }^{13} \mathrm{C}-\mathrm{SS}$ MAS-NMR spectra were recorded using a broadband proton decoupling at a RF field of $87.5 \mathrm{kHz}$ during acquisition, with a spectral width of $75 \mathrm{kHz}$, a $90^{\circ}$ pulse length of $3.3 \mu \mathrm{s}$, a $20 \mathrm{~s}$ recycle delay and an acquisition time of $20 \mathrm{~ms}$. All spectra were collected in duplicate at room temperature $\left(23^{\circ} \mathrm{C}\right)$. Data were analyzed using the Mestrenova ${ }^{\circledR}$ software V6.0 (Mestrelab Research, Santiago de Compostela, Spain). Exponential line broadening 
functions of $50 \mathrm{~Hz}$ were applied to the MAS spectra and chemical shifts were referenced relatively to adamantane (38.25 ppm).

FTIR/ATR data were acquired on a Nicolet smart iTR 6700 spectrometer (Thermo-Nicolet, Madison, WI, USA). Dry solid samples of GO and derivatives were used directly for ATR analysis without sample preparation. Data were analyzed using OMNIC ${ }^{\circledR}$ software (Thermo-Nicolet, Madison, WI, USA). The chemical composition of the surface was investigated by X-ray Photoelectron Spectroscopy, using a PHI 5600-ci spectrometer (Physical Electronics, Eden Prairie, MN, USA). The main XPS chamber was maintained at a base pressure of $<8 \times 10^{-9}$ Torr. A standard magnesium $X$-ray source was used to record survey spectra $(1253.6 \mathrm{eV}, 10 \mathrm{~min})$ and high-resolution spectra, without charge neutralization. The detection angle was set at $45^{\circ}$ with respect to the normal of the surface and the analyzed area was $0.005 \mathrm{~cm}^{2}$ (aperture 4). A peak fitting process was performed where the linear background was first deducted from the original XPS data, after which the spectra were aligned using the $\mathrm{C}-\mathrm{C}$ bond energy ( $284.5 \mathrm{eV}$ ) by using the C 1s of a grounded Highly Oriented Pyrolytic Graphite (HOPG) layer and then fitted using a Gaussian-Lorentzian lineshape. Raman spectroscopy (Renishaw, inVia Reflex, West Dundee, Il, USA) was performed with $514.5 \mathrm{~nm}$ laser excitation at a power of $10 \mathrm{~mW}$. TGA/DTGA analysis were performed using typically $5 \mathrm{mg}$ of dry material with a thermogravimetric analyzer (TGA Q500/Discovery MS, New Castle, DE, USA) under helium (He) with a heat ramp of $5{ }^{\circ} \mathrm{C} / \mathrm{min}$. The $\mathrm{pH}$ of the solutions was measured using color-fixed indicator strips (Macherey-Nagel inc, Bethlehem, PA, USA).

\section{Results and Discussion}

The synthesis of graphene oxide was achieved via the oxidation of graphite using a modified Hummer's method $[57,58]$. After the oxidation step, golden flakes of $\mathrm{GO}$ were suspended in deionized water and reacted with metal salts solutions $\left(\mathrm{SnCl}_{2} \cdot 2 \mathrm{H}_{2} \mathrm{O}, \mathrm{FeCl}_{2} \cdot 4 \mathrm{H}_{2} \mathrm{O}, \mathrm{ZnCl}_{2} \cdot 2 \mathrm{H}_{2} \mathrm{O}, \mathrm{AlCl}_{3} \cdot 6 \mathrm{H}_{2} \mathrm{O}\right.$ and $\mathrm{MgCl}_{2} \cdot 6 \mathrm{H}_{2} \mathrm{O}$ ) under ambient conditions. In the mixture, the metal ions interact with water and $\mathrm{GO}$ to form the hydroxide and some hydrochloric acid is produced in situ. Therefore, the aqueous mixtures were acidic, and their $\mathrm{pH}$ values were evaluated as 1.2, 1.5, 5.4, 2.0 and 5.3, respectively, for GO-Sn, GO-Fe, GO-Zn, GO-Al and GO-Mg suspensions. After $1 \mathrm{~h}$ in the acidic solution, the GO suspensions showed no flocculation or aggregation. This indicates that the reaction products still had a fair number of polar groups attached to their structure, which kept the material in suspension through $\mathrm{H}$ bonding with the oxygenated groups of GO. The solid hybrid materials were collected by centrifugation at high speed (10,000 RPM). The excess of reagents was washed away with a $5 \% \mathrm{HCl}$ solution followed by a copious amount of water to eliminate impurities and free particles not adsorbed on GO. The solution containing unreacted dissolved salts was recuperated in the centrifugation step and recycled for a further batch by simply adding the right amount of metal chloride hydrates to reach the starting concentration (2 M). After lyophilization and proper dehydration, flakes of GO-Sn, GO-Fe, GO-Zn, $\mathrm{GO}-\mathrm{Al}$ and $\mathrm{GO}-\mathrm{Mg}$ ranging from light orange to light brown were recuperated (Figure 1A). 


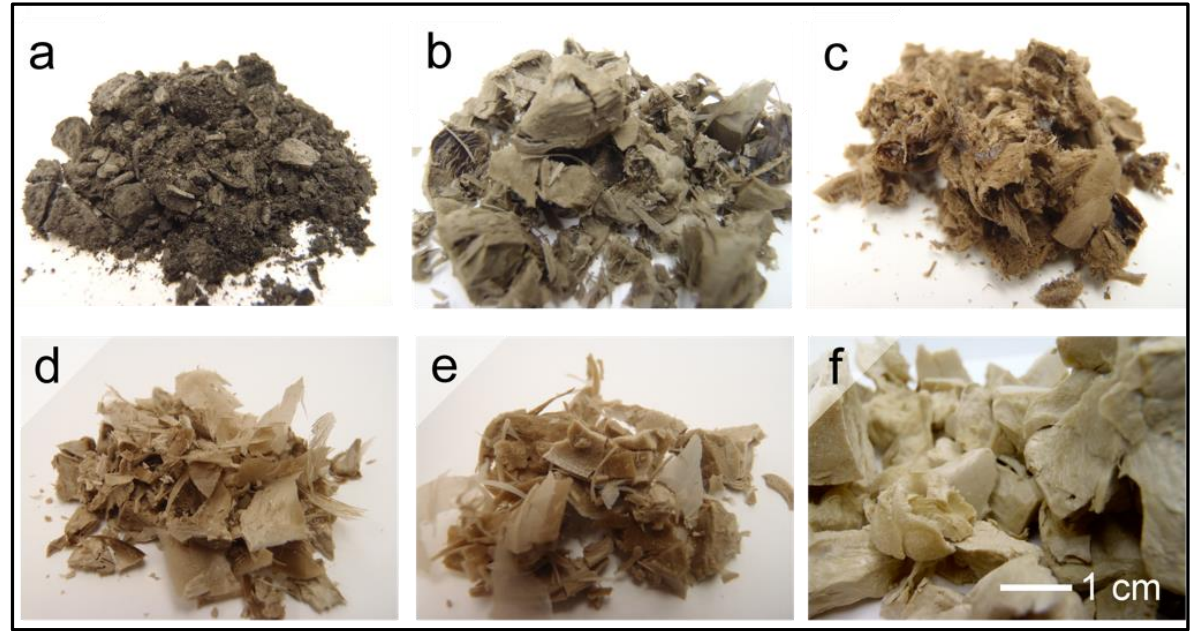

(A)

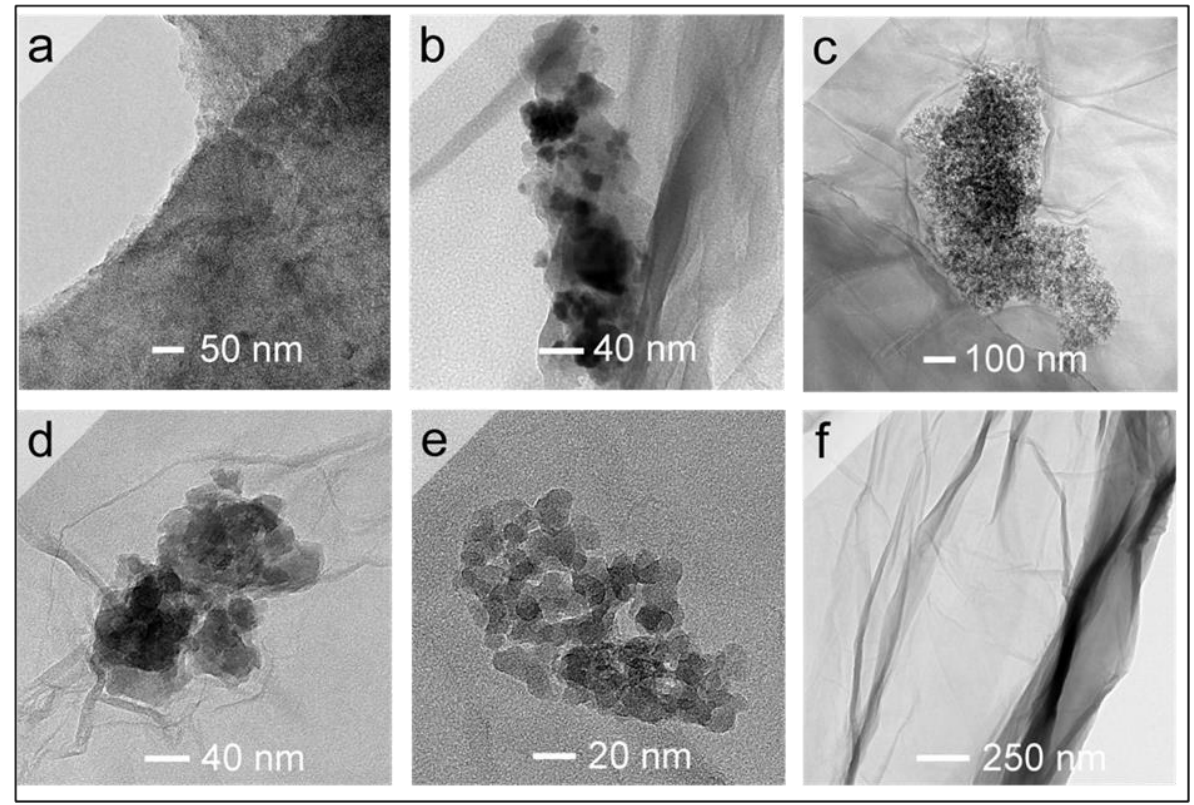

(B)

Figure 1. (A) Optical images; and (B) TEM images of: (a) GO-Sn; (b) GO-Fe; (c) GO-Zn; (d) GO-Al; (e) GO-Mg; and (f) GO materials.

Since reduction can make a great change in the structure of GO, microscopic observation was used to judge the reducing effect of different metal ions on GO [52,53]. TEM images of GO and of the as-dried GO-MO composites are used to show the structure and property changes of GO after reduction. First, Figure 1B shows the formation of spherical NPs on the surface of GO. Noteworthy, the general aspect of GO sheets in GO-Sn, GO-Fe, GO-Zn, GO-Al and GO-Mg remained intact after the reaction. Upon contact with GO, the dissolved metal salts (e.g., $\mathrm{SnCl}_{2} \cdot 2 \mathrm{H}_{2} \mathrm{O}, \mathrm{FeCl}_{2} \cdot 4 \mathrm{H}_{2} \mathrm{O}, \mathrm{ZnCl}_{2} \cdot 2 \mathrm{H}_{2} \mathrm{O}, \mathrm{AlCl}_{3} \cdot 6 \mathrm{H}_{2} \mathrm{O}$ and $\mathrm{MgCl}_{2} \cdot 6 \mathrm{H}_{2} \mathrm{O}$ ) reacted with the oxygenated groups of graphene oxide to produce a complex with the general formula [GO-M $\left.{ }^{\mathrm{n}+}\right][10,52]$. This intermediate may facilitate the reduction of GO either by electron transfer [12] $\left(\mathrm{Sn}^{2+}\right.$ and $\left.\mathrm{Fe}^{2+}\right)$ or acidic solvolysis $\left(\mathrm{Zn}^{2+}, \mathrm{Al}^{3+}\right.$ and $\left.\mathrm{Mg}^{2+}\right)$ [52]. Meanwhile, spontaneous formation of MO NPs was observed on the surface of GO with the approximate particle diameter of 10-40 nm. Noteworthy, the amount of MO NPs found in the hybrid materials was higher when stannous chloride and iron chloride were used as reducing agents. In the case of GO-Sn hybrid, the entire surface of GO was covered uniformly with small NPs of around $10 \mathrm{~nm}$ and the surface had a darker appearance. Upon magnification, a moderate number of larger NPs was observed for GO-Fe. 
Both elements ( $\mathrm{Sn}$ and Fe) were easily identified using EDS (Figure S1 spectroscopy. GO-Sn composite showed a series of EDS peaks at 3.05, 3.27, 3.44, 3.67, 3.91, 4.13 and $4.38 \mathrm{KeV}$. GO-Fe composite had characteristic peaks at 6.40 and $7.06 \mathrm{KeV}$, respectively, for Fe 2p and Fe 3p [59]. In contrast, GO-Zn, GO-Al and GO-Mg composites showed by TEM only few NPs aggregated under islands randomly dispersed on the surface of GO. Therefore, $\mathrm{Zn}, \mathrm{Al}$ and $\mathrm{Mg}$ elements could not be detected with accuracy using EDS. The amounts of metal contained in the GO-MO composites were evaluated by XPS (atomic composition) as $6.8 \%, 1.0 \%, 0.2 \%, 0.2 \%$ and $0.3 \%$, respectively, for elements $\mathrm{Sn}, \mathrm{Fe}, \mathrm{Zn}, \mathrm{Al}$ and $\mathrm{Mg}$ (Table 1).

Table 1. Atomic composition (XPS) of: (a) GO-Sn; (b) GO-Fe; (c) GO-Zn; (d) GO-Al; (e) GO-Mg; and (f) GO materials.

\begin{tabular}{lccccc}
\hline Compound & \% C & \% $\mathbf{~ O}$ & \% $\mathbf{~ M}$ & \% Cl & C/O Ratio \\
\hline GO-Sn & 55.4 & 34.8 & 6.8 & 3.1 & 1.6 \\
GO-Fe & 64.2 & 34.0 & 1.0 & 0.8 & 1.9 \\
GO-Zn & 65.1 & 34.6 & 0.2 & 0.1 & 1.9 \\
GO-Al & 65.6 & 33.9 & 0.2 & 0.1 & 1.9 \\
GO-Mg & 64.9 & 34.4 & 0.3 & 0.2 & 1.9 \\
GO & 6 & 35.7 & 0.0 & 0.0 & 1.8 \\
\hline
\end{tabular}

Table 1 shows the atomic composition of the GO-MO composites (excluding hydrogen atom). The graphene oxide used for the preparation of the hybrids has a $\mathrm{C} / \mathrm{O}$ ratio of 1.8 , which indicates a high degree of oxidation of the starting material [57]. The obtained GO-Fe, GO-Zn, GO-Al and GO-Mg complexes have a slightly higher $\mathrm{C} / \mathrm{O}$ ratio of around 1.9 , which confirms the very mild aspect of the reduction of GO. Stannous chloride in solution in the presence of hydrochloric acid is a powerful reducing agent and can reduce GO [60]. For this, GO-Sn composite should be reduced considerably compared to GO but XPS data (Table 1) show surprisingly lower C/O value (1.6) compared to expectations. Overoxidation of GO was ruled out. This can rather be explained by a significative amount of Sn oxide in the composite increasing the intensity of the $\mathrm{O} 1 \mathrm{~s}$ peak (534 eV) considerably. Because XPS C/O ratio considers the total amount of oxygen atoms in the composite (GO + NPs), it is useless to estimate the level of reduction for GO-MO structures. Infrared spectroscopy (Figure 2A) is well-suited for the monitoring of the reduction process because $\mathrm{GO}$ exhibits a well-defined elongation band at $1720 \mathrm{~cm}^{-1}$ corresponding to the carbonyl region $(\mathrm{C}=\mathrm{O})$ and a band at $1588 \mathrm{~cm}^{-1}$ corresponding to $\mathrm{C}=\mathrm{C}$ elongation (graphitic material) $[6,43]$. The relative ratio of those two signals is representative of the oxygen-containing functional groups vs. the amount of graphitic material found in GO. Upon reduction in contact with the $1 \mathrm{M}$ metal salt solution, the $\mathrm{C}=\mathrm{O}$ band of $\mathrm{GO}$ decreases slightly compared to the $\mathrm{C}=\mathrm{C}$ elongation. The decrease is slightly visible for $\mathrm{GO}-\mathrm{Mg}, \mathrm{GO}-\mathrm{Al}$ and $\mathrm{GO}-\mathrm{Zn}$ and more importantly for GO-Fe and GO-Sn. This decrease in the ratio indicates a higher level of graphitic material, therefore a higher level of reduction in GO-Fe and GO-Sn hybrid, which is supported by the XPS C 1s spectrum (Figure 2B). 


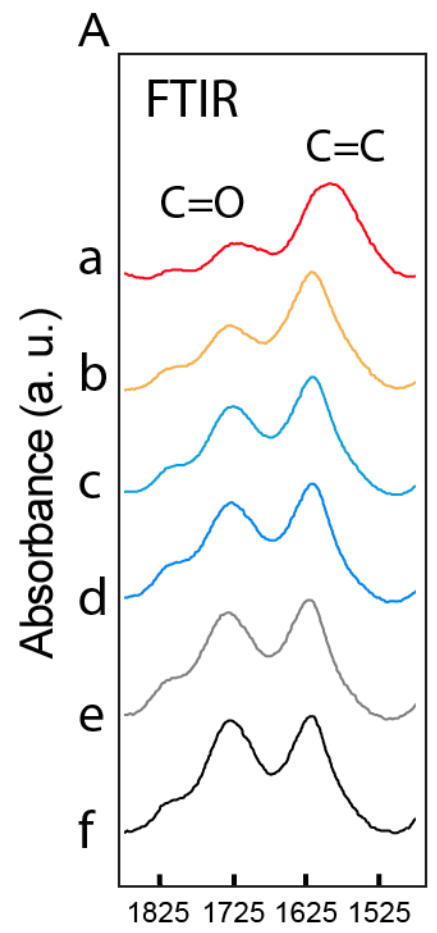

Wavenumber $(\mathrm{cm})$

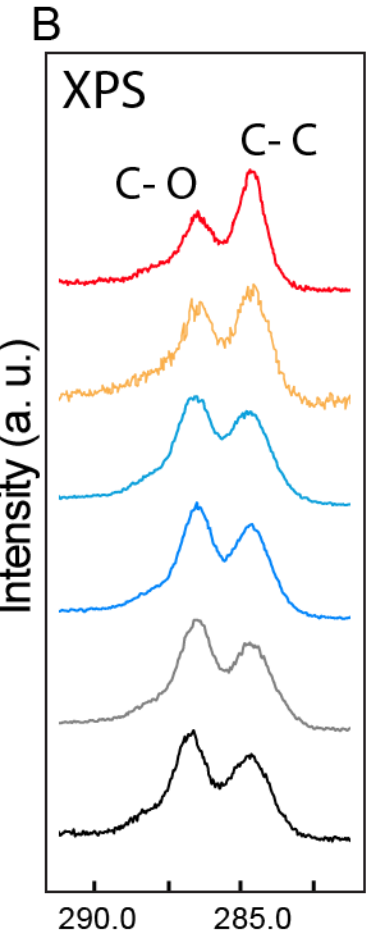

B. E. $(\mathrm{eV})$

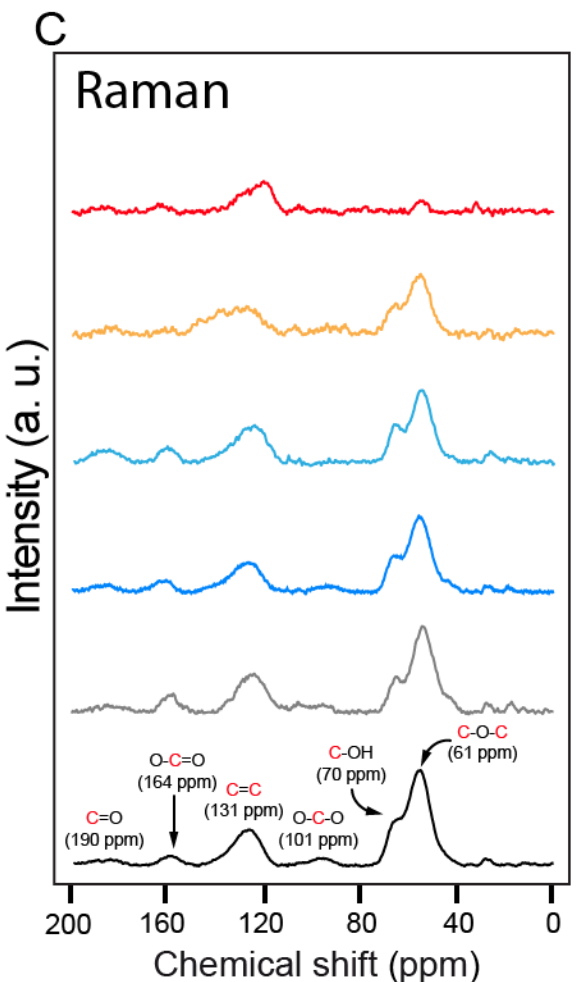

Chemical shift (ppm)

Figure 2. (A) FTIR; (B) XPS C1s; and (C) Raman spectrum of: (a) GO-Sn; (b) GO-Fe; (c) GO-Zn; (d) GO-Al; (e) GO-Mg; and (f) GO materials. ${ }^{13} \mathrm{C}$ direct pulse solid-state NMR (MAS) spectrum of GO-Sn, GO-Fe, GO-Zn, GO-Al, GO-Mg and GO materials (speed of rotation: $12.5 \mathrm{kHz}$ ).

The XPS C1s spectrum of GO (Figure 2B) exhibited two intense bands, one with a symmetrical shape at $284.7 \mathrm{eV}(\mathrm{C}-\mathrm{C})$ and one with an unsymmetrical aspect at $286.9 \mathrm{eV}(\mathrm{C}-\mathrm{O}), 288 \mathrm{eV}(\mathrm{C}=\mathrm{O})$ and $290.0 \mathrm{eV}(\mathrm{O}-\mathrm{C}=\mathrm{O})[6,61]$. The relative intensity of the $\mathrm{C}-\mathrm{C}$ band at $284.7 \mathrm{eV}$ is strongly influenced by the nature of the metal ions used for the reduction $(\mathrm{Sn}>\mathrm{Fe}>\mathrm{Zn}>\mathrm{Al}>\mathrm{Mg}$ ). The band represents the amount of graphitic material in GO and therefore can be used to evaluate qualitatively the fraction of reduced carbon found in the composites. Small amounts $(<1 \%)$ of $\mathrm{Fe}, \mathrm{Zn}, \mathrm{Al}$ and $\mathrm{Mg}$ were detected in the composites by XPS, which implies that those metal ions form a stable complex with GO. XPS spectra (Figures S2 and S3) show Fe 2p $3 / 2$ and Fe2p $p_{1 / 2}$ (711 and $725 \mathrm{eV}$ ) [62,63], Zn 2p $\mathrm{p}_{3 / 2}$ (oxide) (1022 eV) [64], $\mathrm{Al} 2 \mathrm{p}$ (oxide) (76 eV) [65] and Mg 2p (oxide) (53 eV) [66], respectively, for GO-Fe, GO-Zn, GO-Al and GO-Mg composites. For GO-Sn composite, deconvolution showed peaks $(0.9<$ FWHM $<1.4 \mathrm{eV})$ corresponding to $\mathrm{Sn}$ in different valence state. Peaks located around 485.9 and $494.3 \mathrm{eV}$ could be assigned to $\mathrm{Sn}^{0} 3 \mathrm{~d}_{5 / 2}$ and $\mathrm{Sn}^{0} 3 \mathrm{~d}_{3 / 2}$, respectively; peaks at 486.3 and $494.8 \mathrm{eV}$ to $\mathrm{Sn}$ (II, IV) oxide; and peaks at 486.8 and $495.3 \mathrm{eV}$ to Sn (II, V) chloride (Figure S4) $[67,68]$. According to values found in the literature, GO has a standard potential estimated to $-0.4 \mathrm{~V}$ (SHE) at $\mathrm{pH} 4[54,55]$. Because the reduction potential of GO is lower than $\mathrm{Sn}^{2+} \mathrm{Sn}(-0.14 \mathrm{~V})$ [69], GO can supply electron back to trigger spontaneous reduction of $\mathrm{Sn}^{2+}$ into $\mathrm{Sn}$ metal particles [50,56]. This can explain the trace presence of $\mathrm{Sn}^{0}$ in the XPS spectrum (Figure S4). Noteworthy, residual chlorine was detected in small amounts $(0.1-0.2 \%)$ for GO-Zn, GO-Al and GO-Mg. In contrast, GO-Sn and GO-Fe have non-negligible amount of $\mathrm{Cl}$ in their structure and it was estimated to $3.1 \%$ and $0.8 \%$ by atomic composition, respectively, for the as-dried Sn- and Fe-based GO composites.

The Raman spectra of graphene oxide (GO) and GO decorated with various oxide nanoparticles of $\mathrm{Sn}, \mathrm{Fe}, \mathrm{Zn}, \mathrm{Al}$ and $\mathrm{Mg}$ are presented in Figure S5. GO have intense D and $\mathrm{G}$ peaks at $1350 \mathrm{~cm}^{-1}$ and $1592 \mathrm{~cm}^{-1}$, respectively, along with a weak and broad 2D band. D and G peaks are the characteristic peaks of GO $[6,58,61,70]$. The $G$ peak is associated with in-plane bond stretching of sp²-hybridized C atoms in both rings and chains. The $\mathrm{D}$ peak is due to the breathing mode of $\mathrm{sp}^{2}$-hybridized $\mathrm{C}$ atoms 
in aromatic rings. The other five spectra have a similar pattern as the spectrum of GO with slightly blue-shifted D and G peaks. The relative D-band and G-band peak intensities $\left(I_{D} / I_{G}\right)$ reflect the density of defects in the $\mathrm{sp}^{2}$ lattice [71].

The average crystalline size of the $\mathrm{sp}^{2}$ lattice $(L a)$ of each material can be calculated using the intensities of the $\mathrm{D}$ and $\mathrm{G}$ peaks according to the following equation [72]:

$$
L a=2.4 \times 10^{-10} \lambda^{4}{ }_{\text {laser }}\left(I_{G} / I_{D}\right)
$$

where $\lambda_{\text {laser }}$ is the wavelength $(\mathrm{nm})$ of the laser used for Raman measurements. The calculated average crystalline sp ${ }^{2}$ lattice of GO and reduce GO shows an average value around $22 \mathrm{~nm}$ for GO and the $\mathrm{La}$ values of the reduced GO decreased to $18.1 \mathrm{~nm}$. The different values of $L a$ for reduced GO reflect the variation of the defects with the sheet sizes.

The as-dried GO-MO composites were not paramagnetic and were characterized using DP-13 C-SS-NMR (MAS) spectroscopy. ${ }^{13} \mathrm{C}-\mathrm{SS}-\mathrm{NMR}$ (MAS) spectroscopy is a powerful tool to investigate the chemical environment in GO's structure $[61,73]$ and integration of the signals found in the spectra was used to establish the fraction of reduced carbon (FRC) of the GO-based composites with accuracy [57]. Figure 2C shows the DP-MAS spectra of GO and GO-MO composites. The spectrum of GO-Sn shows a high level of graphitization at $134 \mathrm{ppm}$ and some residual signal at $61(\mathrm{O}-\mathrm{C}-\mathrm{O}), 164$ $(\mathrm{O}=\mathrm{C}-\mathrm{O})$ and $190 \mathrm{ppm}(\mathrm{C}=\mathrm{O})$. The data for GO-Fe, GO-Zn, GO-Al and GO-Mg show the characteristic signals of $\mathrm{GO}$ at $61(\mathrm{O}-\mathrm{C}-\mathrm{O}), 70(\mathrm{C}-\mathrm{OH}), 101$ (lactol), $134(\mathrm{C}=\mathrm{C}), 164(\mathrm{O}=\mathrm{C}-\mathrm{O})$ and $190 \mathrm{ppm}(\mathrm{C}=\mathrm{O})$. The fraction of reduced carbon $(\% \mathrm{C}-\mathrm{C})$ contained in each compound was calculated using Equation (S1) (Supplementary Materials).

Remarkably, NMR spectra show a very smooth differential in the intensity from $\mathrm{GO} \rightarrow \mathrm{Mg} \rightarrow \mathrm{Al}$ $\rightarrow \mathrm{Zn} \rightarrow \mathrm{Fe} \rightarrow \mathrm{Sn}$. Table 2 shows the fraction of reduced carbon (FRC) contained in the composite calculated using NMR integration. The FRC was estimated at $26-75 \%$, which confirms the low level of reduction in GO-MO composites. The method of reduction of GO using $1 \mathrm{M}$ of metal salts proposed in this work gives GO materials with a level of reduction similar to the mild method using bacterial respiration (31-95\%), for example [74].

Table 2. Fraction of reduced carbon (\%) calculated by NMR and weight loss (\%) calculated by TG-DTGA for GO-Sn, GO-Fe, GO-Zn, GO-Al, GO-Mg and in GO materials.

\begin{tabular}{lccc}
\hline Entries & Compound & FRC (\%) & Weight Loss (\%) \\
\hline a & GO-Sn & 75 & 16 \\
b & GO-Fe & 38 & 35 \\
c & GO-Zn & 31 & 31 \\
d & GO-Al & 28 & 39 \\
e & GO-Mg & 26 & 39 \\
f & GO & 24 & 45 \\
\hline
\end{tabular}

As observed in Figure 3, TG and DTGA data of GO and GO-MO composites show two distinct drops of mass: one at $106{ }^{\circ} \mathrm{C}$ and a second around $215-240{ }^{\circ} \mathrm{C}$. This first drop indicates a loss of water (4-5\%) trapped in the GO materials, while the second drop represents the loss of labile oxygen-containing functional groups leading to $\mathrm{H}_{2} \mathrm{O}$, which is very useful to compare the level of oxidation among entries [61]. Noteworthy, this second step shows an increasing temperature for GO-MO compared to GO, indicating that the hybrids are more stable thermally. However, around $580-773^{\circ} \mathrm{C}$, a third drop occurs showing the pyrolysis of the GO backbone. A fourth phenomenon starting at $700{ }^{\circ} \mathrm{C}$ is observed as a small increase of the weight, which can be attributed to the oxidation of the different metal. Using TGA integration, the second drop of mass shows that GO-Sn has $15.9 \%$ of labile oxygen atoms in its composition which is three times less than GO $(45 \%)$. These TGA results are consistent with the ratio of the fraction of reduced carbon $(75 \% \div 24 \% \approx 3)$ obtained from NMR 
integrations (Table 2). Because water can be tightly bound to GO materials (4-5\%), it is difficult to use TGA integration to compare all data with accuracy.
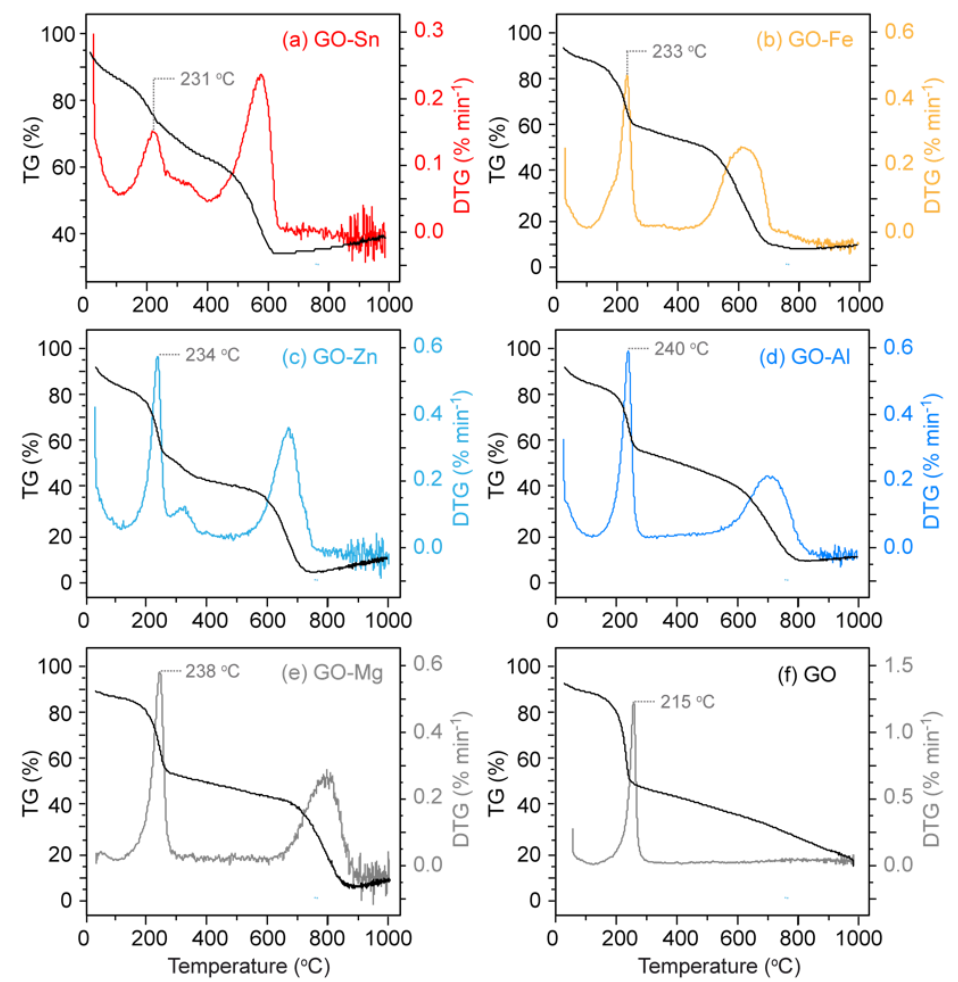

Figure 3. TG and DTG analysis of: (a) GO-Sn; (b) GO-Fe; (c) GO-Zn; (d) GO-Al; (e) GO-Mg; and (f) GO.

Finally, Table 2 shows that $\mathrm{Sn}(\mathrm{II})$ in solution has a greater tendency to reduce GO in ambient conditions compared to other data. According to earlier reports [52,60], a GO-Sn(II) complex is formed in solution and oxidation of $\mathrm{Sn}(\mathrm{II})$ to $\mathrm{Sn}(\mathrm{IV})\left(\mathrm{E}^{0}=-0.77 \mathrm{~V}\right)$ can explain the electron transfer for the reduction of GO according to the following equation:

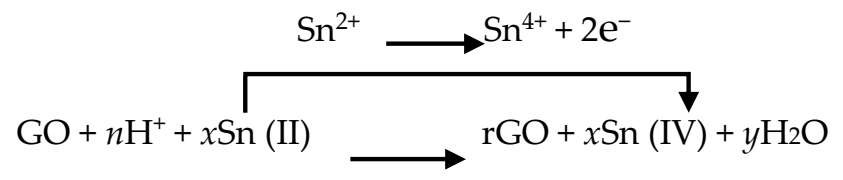

Similarly, we can argue that $\mathrm{Fe}(\mathrm{II})$ can also get oxidized to $\mathrm{Fe}(\mathrm{III})\left(\mathrm{E}^{0}=-0.15 \mathrm{~V}\right)$ [69] in solution after complexation with GO. This can supply one electron for the reduction of GO in GO-Fe composite. Because $\mathrm{Zn}(\mathrm{II}), \mathrm{Al}(\mathrm{III})$ and $\mathrm{Mg}$ (II) cannot reach a higher common oxidation state easily in solution, a similar reduction mechanism based on an electron transfer is not plausible. Similar to metal ions, $\mathrm{Zn}(\mathrm{II}), \mathrm{Al}(\mathrm{III})$ and $\mathrm{Mg}$ (II) have the ability to form complexes through the oxygenated bonds found on GO's surface (GO-O-M). In acidic aqueous solution, the GO-OM bond can break, leading to GO losing one oxygen and the metal ion gaining one. This acidic solvolysis-type mild reduction [52] mechanism can be generalized for other metals according to the following equation:

$$
\mathrm{GO}+\mathrm{M}^{\mathrm{n}+} \mathrm{Cl}_{\mathrm{n}} \underset{\mathrm{H}_{2} \mathrm{O}, \mathrm{r} \text {.r. }}{\stackrel{\mathrm{pH}: 1-5}{\rightarrow}} \mathrm{rGO}-\mathrm{MO}+n \mathrm{HCL}
$$

\section{Conclusions}

We propose a scalable metal ions-assisted homogenous coprecipitation method for the formation of GO@MO hybrids at room temperature in acidic aqueous solution without any additional reducing 
agents or physical treatments to promote the reaction. Various analytical techniques including TEM, XPS, FTIR, Raman analysis, TG-DGTA and especially 13-C SS-NMR spectroscopy clearly showed a mild and tunable reduction of graphene oxide materials with a low fraction of reduced carbon and that GO@MO hybrids could be successfully prepared by the process proposed herein. We found that metal chloride hydrates generate their own hydrochloric acid with the reaction of water and GO, which plays a key role in both eliminating oxygen atoms from graphene oxide and assisting certain metal ions to restore the crystal structure of graphene with electrons. We firmly believe that the unique method presented here deserves to be regarded as a cleaner and more economical preparation process for mass production of GO@MO hybrids with moderate level of oxidization and with a better control of their structure at the nanoscale.

Supplementary Materials: The following are available online at http://www.mdpi.com/2079-4991/10/7/1255/s1, Figure S1: EDS spectra of GO-Sn (up) and GO-Fe (bottom) composites, Figure S2: XPS spectra (Survey) of (a) GO-Sn, (b) GO-Fe, (c) GO-Zn, (d) GO-Al, (e) GO-Mg and (f) GO materials, Figure S3: XPS spectra of (a) GO-Fe, (b) GO-Zn, (c) GO-Al and (d) GO-Mg composites, Figure S4: XPS spectrum and deconvolution of GO-Sn composite, Figure S5: Raman spectrum of (a) GO-Sn, (b) GO-Fe, (c) GO-Zn, (d) GO-Al (e) GO-Mg and (f) GO.

Author Contributions: Conceptualization, P.P.B. and M.S.; methodology, P.P.B.; software, P.P.B.; validation, P.P.B., M.S. and R.I.; formal analysis, P.P.B.; resources, M.S. and R.I.; data curation, P.P.B.; writing-original draft preparation, P.P.B.; writing-review and editing, P.P.B. and M.S.; visualization, P.P.B. and M.S.; supervision, M.S.; funding acquisition, M.S. and R.I. All authors have read and agreed to the published version of the manuscript.

Funding: This research was funded by Fonds Québécois Nature-Technologies (FRQNT), Natural Science and Engineering Research Council of Canada (NSERC), the Canada Research Chairs program (CRC), and Canada Foundation for Innovation (CFI).

Acknowledgments: P.P.B. was supported by Le Fonds Québécois Nature-Technologies (FRQNT). We thank NanoQAM center and QCAM center. We thank A. Arnold (NMR), P. Chevalier (XPS), G. Chamoulaud (TGA), and F. Mahvash (SEM, Raman) for their support collecting data and calibrating instrumentation. This work was supported through funding from the Natural Science and Engineering Research Council of Canada (NSERC), the Canada Research Chairs program (CRC), and Canada Foundation for Innovation (CFI).

Conflicts of Interest: The authors declare no conflict of interest.

\section{References}

1. Khan, M.; Tahir, M.N.; Adil, S.F.; Khan, H.U.; Siddiqui, M.R.H.; Al-warthan, A.A.; Tremel, W. Graphene based metal and metal oxide nanocomposites: Synthesis, properties and their applications. J. Mater. Chem. A 2015, 3, 18753-18808. [CrossRef]

2. Hu, C.; Lu, T.; Chen, F.; Zhang, R. A brief review of graphene-metal oxide composites synthesis and applications in photocatalysis. J. Chin. Adv. Mater. Soc. 2013, 1, 21-39. [CrossRef]

3. Xu, C.; Wang, X.; Zhu, J. Graphene-Metal Particle Nanocomposites. J. Phys. Chem. C 2008, 112, $19841-19845$. [CrossRef]

4. Ogata, C.; Koinuma, M.; Hatakeyama, K.; Tateishi, H.; Asrori, M.Z.; Taniguchi, T.; Funatsu, A.; Matsumoto, Y. Metal permeation into multi-layered graphene oxide. Sci. Rep. 2014, 4, 3647. [CrossRef] [PubMed]

5. Chen, D.; Feng, H.; Li, J. Graphene oxide: Preparation, functionalization, and electrochemical applications. Chem. Rev. 2012, 112, 6027-6053. [CrossRef]

6. Yang, X.; Zhang, X.; Ma, Y.; Huang, Y.; Wang, Y.; Chen, Y. Superparamagnetic graphene oxide--Fe $3 \mathrm{O}_{4}$ nanoparticles hybrid for controlled targeted drug carriers. J. Mater. Chem. 2009, 19, 2710-2714. [CrossRef]

7. Ma, X.; Tao, H.; Yang, K.; Feng, L.; Cheng, L.; Shi, X.; Li, Y.; Guo, L.; Liu, Z. A functionalized graphene oxide-iron oxide nanocomposite for magnetically targeted drug delivery, photothermal therapy, and magnetic resonance imaging. Nano Res. 2012, 5, 199-212. [CrossRef]

8. Cong, H.P.; He, J.J.; Lu, Y.; Yu, S.H. Water-soluble magnetic-functionalized reduced graphene oxide sheets: In situ synthesis and magnetic resonance imaging applications. Small 2010, 6, 169-173. [CrossRef]

9. Zhu, J.; Zhu, T.; Zhou, X.; Zhang, Y.; Lou, X.W.; Chen, X.; Zhang, H.; Hng, H.H.; Yan, Q. Facile synthesis of metal oxide/reduced graphene oxide hybrids with high lithium storage capacity and stable cyclability. Nanoscale 2011, 3, 1084-1089. [CrossRef] 
10. Kim, H.-K.; Park, S.-H.; Yoon, S.-B.; Lee, C.-W.; Jeong, J.H.; Roh, K.C.; Kim, K.-B. In Situ Synthesis of Three-Dimensional Self-Assembled Metal Oxide-Reduced Graphene Oxide Architecture. Chem. Mater. 2014, 26, 4838-4843. [CrossRef]

11. Pendashteh, A.; Mousavi, M.F.; Rahmanifar, M.S. Fabrication of anchored copper oxide nanoparticles on graphene oxide nanosheets via an electrostatic coprecipitation and its application as supercapacitor. Electrochim. Acta 2013, 88, 347-357. [CrossRef]

12. Xiang, C.; Li, M.; Zhi, M.; Manivannan, A.; Wu, N. Reduced graphene oxide/titanium dioxide composites for supercapacitor electrodes: Shape and coupling effects. J. Mater. Chem. 2012, 22, 19161-19167. [CrossRef]

13. Chen, S.; Zhu, J.; Wu, X.; Han, Q.; Wang, X. Graphene Oxide- $\mathrm{MnO}_{2}$ Nanocomposites for Supercapacitors. ACS Nano 2010, 4, 2822-2830. [CrossRef] [PubMed]

14. Sawangphruk, M.; Srimuk, P.; Chiochan, P.; Krittayavathananon, A.; Luanwuthi, S.; Limtrakul, J. High-performance supercapacitor of manganese oxide/reduced graphene oxide nanocomposite coated on flexible carbon fiber paper. Carbon 2013, 60, 109-116. [CrossRef]

15. Stengl, V.; Bakardjieva, S.; Grygar, T.M.; Bludská, J.; Kormunda, M. $\mathrm{TiO}_{2}$-graphene oxide nanocomposite as advanced photocatalytic materials. Chem. Cent. J. 2013, 7, 41. [CrossRef]

16. Zhang, J.; Xiong, Z.; Zhao, X.S. Graphene-metal-oxide composites for the degradation of dyes under visible light irradiation. J. Mater. Chem. 2011, 21, 3634-3640. [CrossRef]

17. Akhavan, O.; Choobtashani, M.; Ghaderi, E. Protein Degradation and RNA Efflux of Viruses Photocatalyzed by Graphene-Tungsten Oxide Composite Under Visible Light Irradiation. J. Phys. Chem. C 2012, 116, 9653-9659. [CrossRef]

18. Chen, C.; Cai, W.; Long, M.; Zhou, B.; Wu, Y.; Wu, D.; Feng, Y. Synthesis of Visible-Light Responsive Graphene Oxide/ $/ \mathrm{TiO}_{2}$ Composites with $\mathrm{p} / \mathrm{n}$ Heterojunction. ACS Nano 2010, 4, 6425-6432. [CrossRef]

19. Yang, Y.; Liu, T. Fabrication and characterization of graphene oxide/zinc oxide nanorods hybrid. Appl. Surf. Sci. 2011, 257, 8950-8954. [CrossRef]

20. Li, X.; Yang, S.; Sun, J.; He, P.; Xu, X.; Ding, G. Tungsten oxide nanowire-reduced graphene oxide aerogel for high-efficiency visible light photocatalysis. Carbon 2014, 78, 38-48. [CrossRef]

21. Xu, S.; Yong, L.; Wu, P. One-Pot, Green, Rapid Synthesis of Flowerlike Gold Nanoparticles/Reduced Graphene Oxide Composite with Regenerated Silk Fibroin As Efficient Oxygen Reduction Electrocatalysts. ACS Appl. Mater. Interfaces 2013, 5, 654-662. [CrossRef] [PubMed]

22. Chen, X.; Wu, G.; Chen, J.; Chen, X.; Xie, Z.; Wang, X. Synthesis of "Clean" and Well-Dispersive Pd Nanoparticles with Excellent Electrocatalytic Property on Graphene Oxide. J. Am. Chem. Soc. 2011, 133, 3693-3695. [CrossRef] [PubMed]

23. Sharma, S.; Ganguly, A.; Papakonstantinou, P.; Miao, X.; Li, M.; Hutchison, J.L.; Delichatsios, M.; Ukleja, S. Rapid Microwave Synthesis of CO Tolerant Reduced Graphene Oxide-Supported Platinum Electrocatalysts for Oxidation of Methanol. J. Phys. Chem. C 2010, 114, 19459-19466. [CrossRef]

24. Choi, Y.; Bae, H.S.; Seo, E.; Jang, S.; Park, K.H.; Kim, B.-S. Hybrid gold nanoparticle-reduced graphene oxide nanosheets as active catalysts for highly efficient reduction of nitroarenes. J. Mater. Chem. 2011, 21, 15431-15436. [CrossRef]

25. Nie, R.; Wang, J.; Wang, L.; Qin, Y.; Chen, P.; Hou, Z. Platinum supported on reduced graphene oxide as a catalyst for hydrogenation of nitroarenes. Carbon 2012, 50, 586-596. [CrossRef]

26. Thien, G.S.H.; Omar, F.S.; Blya, N.I.S.A.; Chiu, W.S.; Lim, H.N.; Yousefi, R.; Sheini, F.-J.; Huang, N.M. Improved Synthesis of Reduced Graphene Oxide-Titanium Dioxide Composite with Highly Exposed 001 Facets and Its Photoelectrochemical Response. Int. J. Photoenergy 2014, 2014, 650583. [CrossRef]

27. Chen, Y.-L.; Hu, Z.-A.; Chang, Y.-Q.; Wang, H.-W.; Zhang, Z.-Y.; Yang, Y.-Y.; Wu, H.-Y. Zinc Oxide/Reduced Graphene Oxide Composites and Electrochemical Capacitance Enhanced by Homogeneous Incorporation of Reduced Graphene Oxide Sheets in Zinc Oxide Matrix. J. Phys. Chem. C 2011, 115, 2563-2571. [CrossRef]

28. Kholmanov, I.N.; Domingues, S.H.; Chou, H.; Wang, X.; Tan, C.; Kim, J.-Y.; Li, H.; Piner, R.; Zarbin, A.J.G.; Ruoff, R.S. Reduced Graphene Oxide/Copper Nanowire Hybrid Films as High-Performance Transparent Electrodes. ACS Nano 2013, 7, 1811-1816. [CrossRef] [PubMed]

29. Parnianchi, F.; Nazari, M.; Maleki, J.; Mohebi, M. Combination of graphene and graphene oxide with metal and metal oxide nanoparticles in fabrication of electrochemical enzymatic biosensors. Int. Nano Lett. 2018, 8 , 229-239. [CrossRef] 
30. Xia, Y.; Li, R.; Chen, R.; Wang, J.; Xiang, L. 3D Architectured Graphene/Metal Oxide Hybrids for Gas Sensors: A Review. Sensors 2018, 18, 1456. [CrossRef]

31. Hao, J.; Ji, L.; Wu, K.; Yang, N. Electrochemistry of ZnO@reduced graphene oxides. Carbon 2018, 130, 480-486. [CrossRef]

32. Guo, D.; Cai, P.; Sun, J.; He, W.; Wu, X.; Zhang, T.; Wang, X.; Zhang, X. Reduced-graphene-oxide/metal-oxide p-n heterojunction aerogels as efficient 3D sensing frameworks for phenol detection. Carbon 2016, 99, 571-578. [CrossRef]

33. Mao, S.; Cui, S.; Lu, G.; Yu, K.; Wen, Z.; Chen, J. Tuning gas-sensing properties of reduced graphene oxide using tin oxide nanocrystals. J. Mater. Chem. 2012, 22, 11009-11013. [CrossRef]

34. Wang, Q.; Cui, X.; Chen, J.; Zheng, X.; Liu, C.; Xue, T.; Wang, H.; Jin, Z.; Qiao, L.; Zheng, W. Well-dispersed palladium nanoparticles on graphene oxide as a non-enzymatic glucose sensor. RSC Adv. 2012, 2, 6245-6249. [CrossRef]

35. Marlinda, A.R.; Huang, N.M.; Muhamad, M.R.; An'amt, M.N.; Chang, B.Y.S.; Yusoff, N.; Harrison, I.; Lim, H.N.; Chia, C.H.; Kumar, S.V. Highly efficient preparation of ZnO nanorods decorated reduced graphene oxide nanocomposites. Mater. Lett. 2012, 80,9-12. [CrossRef]

36. Mura, S.; Jiang, Y.; Vassalini, I.; Gianoncelli, A.; Alessandri, I.; Granozzi, G.; Calvillo, L.; Senes, N.; Enzo, S.; Innocenzi, P.; et al. Graphene Oxide/Iron Oxide Nanocomposites for Water Remediation. ACS Appl. Nano Mater. 2018, 1, 6724-6732. [CrossRef]

37. Yang, X.; Chen, C.; Li, J.; Zhao, G.; Ren, X.; Wang, X. Graphene oxide-iron oxide and reduced graphene oxide-iron oxide hybrid materials for the removal of organic and inorganic pollutants. RSC Adv. 2012, 2, 8821-8826. [CrossRef]

38. Thebo, K.H.; Qian, X.; Wei, Q.; Zhang, Q.; Cheng, H.-M.; Ren, W. Reduced graphene oxide/metal oxide nanoparticles composite membranes for highly efficient molecular separation. J. Mater. Sci. Technol. 2018, 34, 1481-1486. [CrossRef]

39. Chook, S.W.; Chia, C.H.; Zakaria, S.; Ayob, M.K.; Chee, K.L.; Huang, N.M.; Neoh, H.M.; Lim, H.N.; Jamal, R.; Rahman, R. Antibacterial performance of Ag nanoparticles and AgGO nanocomposites prepared via rapid microwave-assisted synthesis method. Nanoscale Res. Lett. 2012, 7, 541. [CrossRef]

40. Richtera, L.; Chudobova, D.; Cihalova, K.; Kremplova, M.; Milosavljevic, V.; Kopel, P.; Blazkova, I.; Hynek, D.; Adam, V.; Kizek, R. The Composites of Graphene Oxide with Metal or Semimetal Nanoparticles and Their Effect on Pathogenic Microorganisms. Materials 2015, 8, 2994-3011. [CrossRef]

41. Park, S.; Lee, K.-S.; Bozoklu, G.; Cai, W.; Nguyen, S.T.; Ruoff, R.S. Graphene Oxide Papers Modified by Divalent Ions-Enhancing Mechanical Properties via Chemical Cross-Linking. ACS Nano 2008, 2, 572-578. [CrossRef] [PubMed]

42. Jana, A.; Scheer, E.; Polarz, S. Synthesis of graphene-transition metal oxide hybrid nanoparticles and their application in various fields. Beilstein J. Nanotechnol. 2017, 8, 688-714. [CrossRef]

43. Nethravathi, C.; Rajamathi, M.; Ravishankar, N.; Basit, L.; Felser, C. Synthesis of graphene oxide-intercalated $\alpha$-hydroxides by metathesis and their decomposition to graphene/metal oxide composites. Carbon 2010, 48 , 4343-4350. [CrossRef]

44. Zhu, J.; He, J. Facile Synthesis of Graphene-Wrapped Honeycomb $\mathrm{MnO}_{2}$ Nanospheres and Their Application in Supercapacitors. ACS Appl. Mater. Interfaces 2012, 4, 1770-1776. [CrossRef]

45. Sohn, M.; Park, E.; Yoo, B.M.; Han, T.H.; Park, H.B.; Kim, H. Metal-assisted mechanochemical reduction of graphene oxide. Carbon 2016, 110, 79-86. [CrossRef]

46. Annamalai, K.P.; Zheng, X.; Gao, J.; Chen, T.; Tao, Y. Nanoporous ruthenium and manganese oxide nanoparticles/reduced graphene oxide for high-energy symmetric supercapacitors. Carbon 2019, 144, 185-192. [CrossRef]

47. El-Shafai, N.M.; El-Khouly, M.E.; El-Kemary, M.; Ramadan, M.S.; Masoud, M.S. Graphene oxide-metal oxide nanocomposites: Fabrication, characterization and removal of cationic rhodamine B dye. RSC Adv. 2018, 8, 13323-13332. [CrossRef]

48. Ishaq, S.; Moussa, M.; Kanwal, F.; Ehsan, M.; Saleem, M.; Van, T.N.; Losic, D. Facile synthesis of ternary graphene nanocomposites with doped metal oxide and conductive polymers as electrode materials for high performance supercapacitors. Sci. Rep. 2019, 9, 5974. [CrossRef]

49. Williams, G.; Seger, B.; Kamat, P.V. $\mathrm{TiO}_{2}-$ Graphene Nanocomposites. UV-Assisted Photocatalytic Reduction of Graphene Oxide. ACS Nano 2008, 2, 1487-1491. [CrossRef] 
50. Kong, B.-S.; Geng, J.; Jung, H.-T. Layer-by-layer assembly of graphene and gold nanoparticles by vacuum filtration and spontaneous reduction of gold ions. Chem. Commun. 2009, 16, 2174-2176. [CrossRef]

51. Zhuo, Q.; Gao, J.; Peng, M.; Bai, L.; Deng, J.; Xia, Y.; Ma, Y.; Zhong, J.; Sun, X. Large-scale synthesis of graphene by the reduction of graphene oxide at room temperature using metal nanoparticles as catalyst. Carbon 2013, 52, 559-564. [CrossRef]

52. Chua, C.K.; Pumera, M. Chemical reduction of graphene oxide: A synthetic chemistry viewpoint. Chem. Soc. Rev. 2014, 43, 291-312. [CrossRef] [PubMed]

53. Pei, S.; Cheng, H.-M. The reduction of graphene oxide. Carbon 2012, 50, 3210-3228. [CrossRef]

54. Mei, X.; Ouyang, J. Ultrasonication-assisted ultrafast reduction of graphene oxide by zinc powder at room temperature. Carbon 2011, 49, 5389-5397. [CrossRef]

55. Zhou, M.; Wang, Y.; Zhai, Y.; Zhai, J.; Ren, W.; Wang, F.; Dong, S. Controlled synthesis of large-area and patterned electrochemically reduced graphene oxide films. Chemistry 2009, 15, 6116-6120. [CrossRef]

56. Zhou, X.; Huang, X.; Qi, X.; Wu, S.; Xue, C.; Boey, F.Y.C.; Yan, Q.; Chen, P.; Zhang, H. In Situ Synthesis of Metal Nanoparticles on Single-Layer Graphene Oxide and Reduced Graphene Oxide Surfaces. J. Phys. Chem. C 2009, 113, 10842-10846. [CrossRef]

57. Marcano, D.C.; Kosynkin, D.V.; Berlin, J.M.; Sinitskii, A.; Sun, Z.; Slesarev, A.; Alemany, L.B.; Lu, W.; Tour, J.M. Improved Synthesis of Graphene Oxide. ACS Nano 2010, 4, 4806-4814. [CrossRef]

58. Brisebois, P.P.; Siaj, M. Harvesting graphene oxide-Years 1859 to 2019: A review of its structure, synthesis, properties and exfoliation. J. Mater. Chem. C 2020, 8, 1517-1547. [CrossRef]

59. Kaye, G.W.C.; Laby, T.H. Kaye and Labye Tables of Physical Constants \& Chemical Constants, 16th ed.; National Physical Laboratory: Middlessex, UK, 1995.

60. Kumar, N.A.; Gambarelli, S.; Duclairoir, F.; Bidan, G.; Dubois, L. Synthesis of high quality reduced graphene oxide nanosheets free of paramagnetic metallic impurities. J. Mater. Chem. A 2013, 1, 2789-2794. [CrossRef]

61. Brisebois, P.P.; Kuss, C.; Schougaard, S.B.; Izquierdo, R.; Siaj, M. New Insights into the Diels-Alder Reaction of Graphene Oxide. Chemistry 2016, 22, 5849-5852. [CrossRef]

62. Chen, W.; Li, S.; Chen, C.; Yan, L. Self-assembly and embedding of nanoparticles by in situ reduced graphene for preparation of a 3D graphene/nanoparticle aerogel. Adv. Mater. 2011, 23, 5679-5683. [CrossRef] [PubMed]

63. Kamiya, K.; Hashimoto, K.; Nakanishi, S. Instantaneous one-pot synthesis of Fe-N-modified graphene as an efficient electrocatalyst for the oxygen reduction reaction in acidic solutions. Chem. Commun. 2012, 48, 10213-10215. [CrossRef] [PubMed]

64. Lv, R.; Wang, X.; Lv, W.; Xu, Y.; Ge, Y.; He, H.; Li, G.; Wu, X.; Li, X.; Li, Q. Facile synthesis of ZnO nanorods grown on graphene sheets and its enhanced photocatalytic efficiency. J. Chem. Technol. Biotechnol. 2015, 90, 550-558. [CrossRef]

65. Maruyama, B.; Ohuchi, F.S.; Rabenberg, L. Catalytic carbide formation at aluminium-carbon interfaces. J. Mater. Sci. Lett. 1990, 9, 864-866. [CrossRef]

66. Ardizzone, S.; Bianchi, C.L.; Fadoni, M.; Vercelli, B. Magnesium salts and oxide: An XPS overview. Appl. Surf. Sci. 1997, 119, 253-259. [CrossRef]

67. Paparazzo, E. On the interpretation of XPS spectra of metal (Pt, Pt-Sn) nanoparticle/graphene systems. Carbon 2013, 63, 578-581. [CrossRef]

68. Liu, C.-J.; Huang, H.; Cao, G.-Z.; Xue, F.-H.; Paredes Camacho, R.A.; Dong, X.-L. Enhanced Electrochemical Stability of Sn-Carbon Nanotube Nanocapsules as Lithium-Ion Battery Anode. Electrochim. Acta 2014, 144, 376-382. [CrossRef]

69. Bard, A.J.; Parsons, R.; Jordan, J. International Union of Pure and Applied Chemistry. Standard Potentials in Aqueous Solution, 1st ed.; Marcel Dekker: New York, NY, USA, 1985.

70. Ferrari, A.C.; Robertson, J. Interpretation of Raman spectra of disordered and amorphous carbon. Phys. Rev. B 2000, 61, 14095-14107. [CrossRef]

71. Al Shboul, A.M.; Siaj, M.; Claverie, J.P. Selective Process To Extract High-Quality Reduced Graphene Oxide Leaflets. ACS Appl. Nano Mater. 2018, 1, 5920-5926. [CrossRef]

72. Cançado, L.G.; Takai, K.; Enoki, T.; Endo, M.; Kim, Y.A.; Mizusaki, H.; Jorio, A.; Coelho, L.N.; Magalhães-Paniago, R.; Pimenta, M.A. General equation for the determination of the crystallite size La of nanographite by Raman spectroscopy. Appl. Phys. Lett. 2006, 88, 163106. [CrossRef] 
73. Lerf, A.; He, H.; Forster, M.; Klinowski, J. Structure of Graphite Oxide Revisited. J. Phys. Chem. B 1998, 102, 4477-4482. [CrossRef]

74. Salas, E.C.; Sun, Z.; Lüttge, A.; Tour, J.M. Reduction of Graphene Oxide via Bacterial Respiration. ACS Nano 2010, 4, 4852-4856. [CrossRef] [PubMed]

(C) 2020 by the authors. Licensee MDPI, Basel, Switzerland. This article is an open access article distributed under the terms and conditions of the Creative Commons Attribution (CC BY) license (http://creativecommons.org/licenses/by/4.0/). 